Prepared for the U.S. Department of Energy

under Contract DE-AC05-76RL01830

\title{
RECOMMENDATIONS FOR UO3 PLANT BIOASSAY
}

\author{
EH Carbaugh
}

July 2010

\section{Pacific Northwest}




\section{Contents}

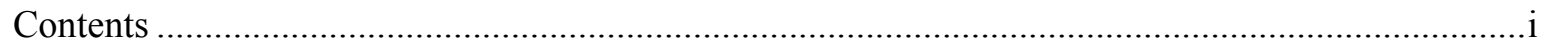

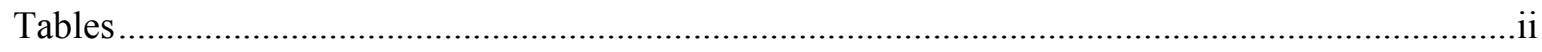

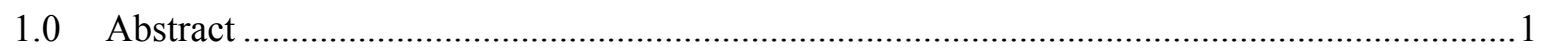

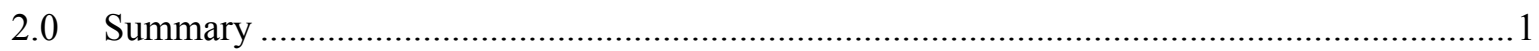

3.0 Assumptions:

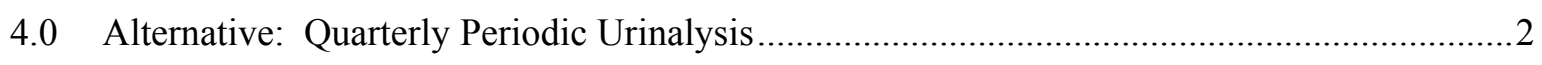

5.0 Alternative: Monthly Periodic Urinalysis ....................................................................

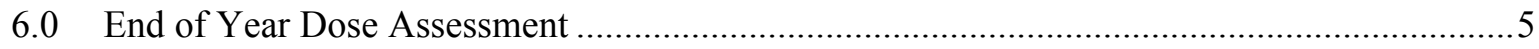

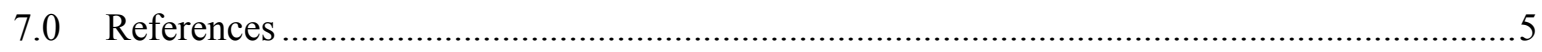




\section{Tables}

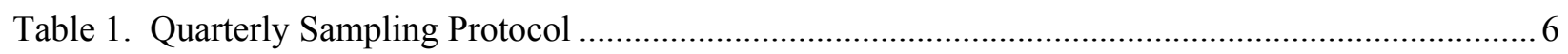

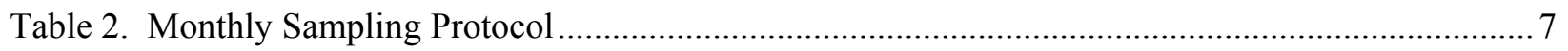

Table A.1. Urinary excretion fractions for absorption types F, M and UO3 Plant, based on acute

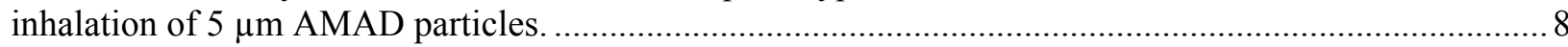

Table A.2. Screening levels for various periodic monitoring intervals for Hanford UO3 material, assuming acute inhalation of 5- $\mu \mathrm{m}$ AMAD particles. 


\section{RECOMMENDATIONS FOR UO3 PLANT BIOASSAY}

\subsection{Abstract}

Alternative urine bioassay programs are described for application with decontamination and decommissioning activities at the Hanford UO3 Plant. The alternatives are based on quarterly or monthly urine bioassay for recycled uranium, assuming multiple acute inhalation intakes of recycled uranium occurring over a year. The inhalations are assumed to be $5 \mu \mathrm{m}$ AMAD particles of $80 \%$ absorption type $\mathrm{F}$ and $20 \%$ absorption type M. Screening levels, expressed as daily uranium mass excretion rates in urine, and the actions associated with these levels are provided for both quarterly and monthly sampling frequencies.

\subsection{Summary}

Work activities associated with the decommissioning and demolition of the UO3 processing facilities (notably 224-U Building) have warranted establishing a bioassay monitoring program considering the specific UO3 source material. A specific monitoring program for this material and facility was designed in the 1980s when the facility was in routine production operation, but terminated in the mid-1990s when it was placed in a long-term surveillance mode. Consequently, no facility-specific monitoring was addressed when the Hanford internal dosimetry technical basis documents were revised to incorporate new biokinetic models (effective January 2010).

This brief report describes two alternative periodic bioassay monitoring programs appropriate for UO3 work, and the technical basis underlying them. The two alternatives address urinalysis at either quarterly or monthly sampling frequencies. Both sampling frequencies are capable of fulfilling Department of Energy monitoring requirements. Monthly sampling provides for a substantially lower minimum detectable dose, with more timely capability for intake verification, however the cost of monthly bioassay is three times that for quarterly bioassay. In vivo measurements (chest counting or whole body counting) are not appropriate bioassay for periodic UO3 bioassay. The capabilities of the two bioassay monitoring frequencies are described below.

Solubility studies performed in 1985 and summarized in the 1991 Technical Basis for Internal Dosimetry at Hanford (Reference 1) identified UO3 material as exhibiting solubility corresponding to $80 \%$ inhalation class D and 20\% inhalation class W. According to Methods and Models of the Hanford Internal Dosimetry Program (PNNL-MA-860, Reference 2) this now corresponds to $80 \%$ absorption type F and 20\% absorption type $\mathrm{M}$.

Screening levels, expressed as daily uranium mass excretion rates in urine, and the actions associated with these levels are shown in Tables 1 and 2 for quarterly and monthly sampling frequencies, respectively. Samples may be collected using approximate 24-h sampling protocol (kit code 1) with direct comparison to screening levels. Alternatively, if partial day samples are obtained (e.g., kit codes 2, 6 , or 7), sample results must be normalized to daily excretion rates for comparison with screening levels. As used in this report, "dose" refers to committed effective dose. The supporting derivation of these screening levels is shown in the Appendix. 


\subsection{Assumptions:}

1. The primary design criteria for bioassay monitoring programs is specified in Section 2.3.1 of the Hanford Internal Dosimetry Program Manual (PNL-MA-552, Reference 3). Notably, programs will be capable of detecting an intake potentially resulting in a committed effective dose of 100 mrem, to the extent technical site contractors and technical capabilities allow.

2. A second design goal used in this report is for a monthly program to be capable of detecting UO3 intakes in a year that would result in a committed effective dose of $10 \mathrm{mrem}$.

3. A third design goal is based on interpreting 10 CFR 835.702(b) to imply that single bioassay measurements should be capable of identifying 10 mrem committed effective dose from an intake where practicable given standard bioassay methods.

4. The source material (UO3) is $80 \%$ Type $\mathrm{F}$ and $20 \%$ Type $\mathrm{M}$ recycled uranium.

5. The environmental screening level is $0.2 \mu \mathrm{g} / \mathrm{d}$. (Reference 2, Table 7.33)

6. The potential exposure scenario is multiple acute exposures in a year, assuming one intake per monitoring interval.

7. The biokinetic models are per Reference 2 .

8. Dose coefficients $e(50)$ for recycled uranium are per Reference 2, Table 7.20.

Type F: $\quad 2.18 \mathrm{E}-03 \mathrm{rem} / \mathrm{mg}-\mathrm{U}$

Type M: $\quad 6.50 \mathrm{E}-03 \mathrm{rem} / \mathrm{mg}-\mathrm{U}$

UO3: $\quad 3.04 \mathrm{E}-03 \mathrm{rem} / \mathrm{mg}-\mathrm{U}(80 \%$ Type $\mathrm{F}$ and $20 \%$ Type $\mathrm{M})$

\subsection{Alternative: Quarterly Periodic Urinalysis}

Design basis:

1. A screening level is established for dose assessment based on a single measurement identifying an intake that may exceed 10 mrem committed effective dose. (10 CFR 835.702(b) criterion)

2. A supplemental screening level is based on the potential for $100 \mathrm{mrem}$ in a calendar year.

3. Screening levels are set assuming detection of a single acute intake 90 days prior to bioassay.

Description:

1. Quarterly urinalysis for $\mathrm{U} 238$.

2. Results $>0.2 \mu \mathrm{g} / \mathrm{d}$ will be high-flagged by lab per routine GEL protocol with notification to Hanford Internal Dosimetry.

3. Results $>0.2 \mu \mathrm{g} / \mathrm{d}$ but not exceeding $0.6 \mu \mathrm{g} / \mathrm{d}$ will be considered minor exposure not warranting action. 
a. Rapid notification is not required.

b. A normal result letter will be sent to the worker.

c. The $0.6 \mu \mathrm{g} / \mathrm{d}$ level is based on $0.2 \mu \mathrm{g} / \mathrm{d}$ environmental screening level plus $0.4 \mu \mathrm{g} / \mathrm{d}$ as the derived level for excretion at 90 days following a UO3 intake resulting in a dose of $10 \mathrm{mrem}$. The $0.6 \mu \mathrm{g} / \mathrm{d}$ level meets the 10 CFR 835.702(b) criterion.

4. Results between $0.6 \mu \mathrm{g} / \mathrm{d}$ and $1 \mu \mathrm{g} / \mathrm{d}$ will be considered potentially indicative of potential dose in excess of $10 \mathrm{mrem}$ (for the interval).

a. Rapid notification will be provided to contractor.

b. Dose assessment will be performed at the end of the calendar year based on all associated bioassays.

c. It is assumed that exposure is associated with routine work and does not require U236 for determination of occupational versus nonoccupational exposure.

d. The option to perform U236 analysis on periodic sample residual is at the discretion of the contractor. If U236 analysis is performed and no U-236 is detected, then a UO3 occupational intake will not be confirmed.

5. Results $>1 \mu \mathrm{g} / \mathrm{d}$ (corresponding to urine excretion 90 days following an acute intake that would result in a committed effective dose of $25 \mathrm{mrem}$ ) will be considered potentially indicative of dose in excess of $100 \mathrm{mrem}$ if exposure is sustained for 1 year.

a. A U236 analysis will be performed on the remainder of the periodic sample as a matter of default procedure by Hanford Internal Dosimetry. If U236 is detected, occupational dose will be assessed.

b. The $1 \mu \mathrm{g} / \mathrm{d}$ level is based on $0.2 \mu \mathrm{g} / \mathrm{d}$ environmental screening level plus $0.989 \mu \mathrm{g} / \mathrm{d}$ projected urine excretion 90 days following an acute 25 mrem intake, rounded to one significant figure $(1 \mu \mathrm{g} / \mathrm{d})$.

\subsection{Alternative: Monthly Periodic Urinalysis}

Design basis:

1. 100 mrem from UO3 intakes in a year is easily met.

2. 10 mrem from UO3 intakes in a year will not likely go unreported.

3. $0.8 \mathrm{mrem}(10 \mathrm{mrem} / 12$ months $)$ from UO3 intakes in a monthly interval will not go unreported.

4. A dose assessment is required if the annual dose indicated from periodic monitoring might exceed $10 \mathrm{mrem}$.

5. Screening levels are set assuming detection of a single acute intake 30 days prior to bioassay.

\section{Description:}

1. Monthly urinalysis for $\mathrm{U} 238$; kit code 1 is recommended. 
2. Results $>0.2 \mu \mathrm{g} / \mathrm{d}$ will be high-flagged by lab per routine GEL protocol with notification to Hanford Internal Dosimetry.

3. Results $>0.2 \mu \mathrm{g} / \mathrm{d}$ but not exceeding $0.4 \mu \mathrm{g} / \mathrm{d}$ will be considered minor exposure not warranting action.

a. Rapid notification is not required.

b. A normal result letter will be sent to the worker.

c. The $0.4 \mu \mathrm{g} / \mathrm{d}$ level is based on $0.2 \mu \mathrm{g} / \mathrm{d}$ environmental screening level plus $0.16 \mu \mathrm{g} / \mathrm{d}$ as the derived level for detection at one month following an intake that could result in $0.83 \mathrm{mrem}$, with the sum rounded to one significant figure $(0.4 \mu \mathrm{g} / \mathrm{d})$.

d. Twelve such monthly intakes would result in a committed effective dose for a year of 10 mrem, which is considered a dose of no consequence with regard to recording for periodic bioassay programs (10 CFR 835.702(b).

4. Results $>0.4 \mu \mathrm{g} / \mathrm{d}$ but not exceeding $2 \mu \mathrm{g} / \mathrm{d}$ will be considered minor occupational exposure from normal work activities requiring end-of-calendar-year dose assessment. The potential exists for cumulative dose from UO3 intakes to exceed $10 \mathrm{mrem}$, but will not exceed $100 \mathrm{mrem}$.

a. Rapid notification will be provided to the contractor.

b. The worker will be advised by letter that an end-of-year dose assessment will be performed.

c. Contractor has options for a U236 analysis and a dose assessment for the monthly interval.

d. The $2 \mu \mathrm{g} / \mathrm{d}$ level is based on $0.2 \mu \mathrm{g} / \mathrm{d}$ environmental screening level plus $1.6 \mu \mathrm{g} / \mathrm{d}$ as the derived level for detection at one month following an intake that could result in $8.3 \mathrm{mrem}$, with the sum rounded to one significant figure $(2 \mu \mathrm{g} / \mathrm{d})$.

e. Twelve such monthly intakes would result in a committed effective dose for a year of 100 mrem, which is the design basis for Hanford bioassay programs.

5. Results $>2 \mu \mathrm{g} / \mathrm{d}$ but not exceeding $7 \mu \mathrm{g} /$ may be indicative of a potential dose in excess of 10 mrem for the sampled interval and could indicate a dose in excess of $100 \mathrm{mrem}$ if intake levels are sustained for 1 year.

a. Rapid notification will be provided to contractor.

b. Dose assessment will be performed at the end of the calendar year based on all associated bioassays.

c. The default assumption is that exposure is associated with routine work and does not require U236 analysis for determination of occupational versus nonoccupational exposure.

d. The option to perform a U236 analysis on the periodic sample residual is at the discretion of the contractor. If U236 analysis is requested and the analyte is not detected, then a UO3 occupational intake will not be confirmed.

6. Results $>7 \mu \mathrm{g} / \mathrm{d}$ will be considered potentially indicative of an acute intake one month prior which could have exceeded the screening level for transient chemical toxicity, assuming highly soluble (Type F) material.

a. Rapid notification will be provided to the contractor.

b. A U236 analysis will be performed on the remainder of the periodic sample as a matter of default procedure by Hanford Internal Dosimetry.

c. Occupational dose will be assessed based on detection of U-236 in the supplemental analysis.

d. The $7 \mu \mathrm{g} / \mathrm{d}$ chemical toxicity level is from Reference 2, Table 7.24. 


\subsection{End of Year Dose Assessment}

1. Unless specific intake dates are identified, it is assumed that all days had an equally likely potential for intake.

2. If multiple acute intakes are indicated from the data, the dose may be assessed as an approximation of chronic exposure, using the method of Equation 7.2 in Section 7.5.2 of PNNLMA-860 (Reference 2). Alternatively, intakes may be assessed for single intervals, if data so support.

\subsection{References}

Sula, MJ, Carbaugh, EH, and Bihl, DE. Technical Basis for Internal Dosimetry at Hanford, PNL-6866, Pacific Northwest National Laboratory. July 1991.

Pacific Northwest National Laboratory (PNNL). Methods and Models of the Hanford Internal Dosimetry Program, PNNL-MA-860, Richland, Washington. (Internal manual). Copy maintained in the Hanford Internal Dosimetry Program files and available online by searching, PNNL-15614@ http://www.pnl.gov/publications/. Effective date, January 1, 2010.

Pacific Northwest National Laboratory (PNNL). Hanford Internal Dosimetry Program Manual, PNLMA-552, Richland, Washington. (Internal manual.) Copy maintained in the Hanford Internal Dosimetry Program files and available online by searching, PNNL-15613@ http://www.pnl.gov/publications/. Effective date, January 1, 2010. 


\section{SUMMARY OF SCREENING LEVELS FOR UO3 BIOASSAY PROGRAMS}

Table 1. Quarterly Sampling Protocol $\{$ TA $\backslash 1$ "Table 1. Quarterly Sampling Protocol" $\backslash s$ "Table 1. Quarterly Sampling Protocol" \c 1 \}

\begin{tabular}{cll}
\hline \multicolumn{1}{c}{ Level } & Basis for Action & Action \\
\hline$\leq 0.2 \mu \mathrm{g} / \mathrm{d}$ & $\begin{array}{l}\text { Below Environmental } \\
\text { Screening Level. }\end{array}$ & $\begin{array}{l}\text { No action; normal result letter } \\
\text { automatically generated. }\end{array}$ \\
0.2 to $0.6 \mu \mathrm{g} / \mathrm{d}$ & $\begin{array}{l}\text { Routine low level exposure } \\
\text { indicated. Below dose } \\
\text { recording and investigation } \\
\text { levels. }\end{array}$ & $\begin{array}{l}\text { No action. Normal result letter } \\
\text { generated by Internal Dosimetry. }\end{array}$ \\
$>0.6 \mu \mathrm{g} / \mathrm{d}$ but & $\begin{array}{l}\text { Potential intake resulting in a } \\
\text { committed effective dose in } \\
\text { excess of } 10 \text { mrem. }\end{array}$ & $\begin{array}{l}\text { Rapid notification to contractor. } \\
\text { Evaluation report at end of } \\
\text { calendar year based on total data. } \\
\text { Option for U236 analysis. }\end{array}$ \\
& $\begin{array}{l}\text { Potential intake resulting in a } \\
\text { committed effective dose in } \\
\text { excess of } 25 \text { mrem. }\end{array}$ & $\begin{array}{l}\text { Rapid notification to contractor. } \\
\text { Default U236 analysis on sample } \\
\text { remainder. Possible collection of } \\
\text { additional samples. Evaluation } \\
\text { report. }\end{array}$ \\
\hline
\end{tabular}




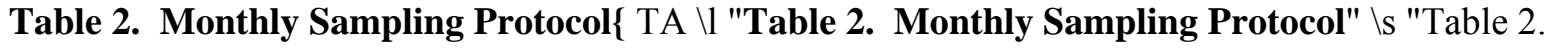
Monthly Sampling Protocol" \c 1 \}

\begin{tabular}{|c|c|c|}
\hline Level & Basis for Action & Action \\
\hline$\leq 0.2 \mu \mathrm{g} / \mathrm{d}$ & $\begin{array}{l}\text { Below Environmental } \\
\text { Screening Level. }\end{array}$ & $\begin{array}{l}\text { No action; normal result letter } \\
\text { automatically generated. }\end{array}$ \\
\hline 0.2 to $0.4 \mu \mathrm{g} / \mathrm{d}$ & $\begin{array}{l}\text { Routine low level exposure } \\
\text { indicated, but resulting doses } \\
\text { from annual intake would be } \\
\text { below the dose recording level } \\
\text { of } 10 \text { mrem for routine } \\
\text { monitoring. }\end{array}$ & $\begin{array}{l}\text { No action. Normal result letter } \\
\text { generated by Internal Dosimetry. }\end{array}$ \\
\hline $\begin{array}{c}>0.4 \mu \mathrm{g} / \mathrm{d} \text { but } \leq 2 \\
\mu \mathrm{g} / \mathrm{d}\end{array}$ & $\begin{array}{l}\text { Sustained intake levels for } 1 \\
\text { year could indicate a } \\
\text { committed effective dose } \\
\text { between } 10 \text { mrem and } 100 \\
\text { mrem. }\end{array}$ & $\begin{array}{l}\text { Rapid notification to contractor. } \\
\text { Evaluation report at end of } \\
\text { calendar year based on total data. } \\
\text { Option for U } 236 \text { analysis. }\end{array}$ \\
\hline $\begin{array}{c}>2 \mu \mathrm{g} / \mathrm{d} \text { but } \\
\leq 7 \mu \mathrm{g} / \mathrm{d}\end{array}$ & $\begin{array}{l}\text { Single monthly intake could } \\
\text { exceed } 10 \text { mrem committed } \\
\text { effective dose. Cumulative } \\
\text { annual intake could exceed } \\
100 \text { mrem. }\end{array}$ & $\begin{array}{l}\text { Rapid notification to contractor. } \\
\text { Option for evaluation report for } \\
\text { immediate interval, or at end of } \\
\text { calendar year based on total data. } \\
\text { Option for U } 236 \text { analysis. }\end{array}$ \\
\hline$>7 \mu \mathrm{g} / \mathrm{d}$ & $\begin{array}{l}\text { Potential intake that might } \\
\text { have exceeded screening level } \\
\text { for transient chemical toxicity. }\end{array}$ & $\begin{array}{l}\text { Rapid notification to contractor. } \\
\text { Default U236 analysis on sample } \\
\text { remainder. Possible collection of } \\
\text { additional samples or referral to } \\
\text { Occupational Medicine. } \\
\text { Evaluation report. }\end{array}$ \\
\hline
\end{tabular}




\section{APPENDIX}

Table A.1. Urinary excretion fractions for absorption types F, M and UO3 Plant, based on acute inhalation of $5 \mu \mathrm{m}$ AMAD particles. $\{\mathrm{TA} \backslash 1$ "Table A.1. Urinary excretion fractions for absorption types F, M and UO3 Plant, based on acute inhalation of $\mathbf{5}$ um AMAD particles." $\backslash \mathrm{s}$ "Table A.1. Urinary excretion fractions for absorption types F, M and UO3 Plant, based on acute inhalation of $5 \mu \mathrm{m}$ AMAD particles." \c 1 \}

\begin{tabular}{cccc}
\hline $\begin{array}{c}\text { Day Post } \\
\text { Intake }\end{array}$ & Type F $^{(\text {a) }}$ & Type M $^{(\mathrm{a})}$ & UO3 Plant \\
\hline 1 & $1.84 \mathrm{E}-01$ & $2.32 \mathrm{E}-02$ & $1.52 \mathrm{E}-01$ \\
2 & $6.38 \mathrm{E}-03$ & $1.12 \mathrm{E}-03$ & $5.33 \mathrm{E}-03$ \\
3 & $5.14 \mathrm{E}-03$ & $8.53 \mathrm{E}-04$ & $4.28 \mathrm{E}-03$ \\
5 & $4.21 \mathrm{E}-03$ & $7.35 \mathrm{E}-04$ & $3.52 \mathrm{E}-03$ \\
7 & $3.50 \mathrm{E}-03$ & $6.46 \mathrm{E}-04$ & $2.93 \mathrm{E}-03$ \\
14 & $1.94 \mathrm{E}-03$ & $4.47 \mathrm{E}-04$ & $1.64 \mathrm{E}-03$ \\
30 & $6.81 \mathrm{E}-04$ & $2.66 \mathrm{E}-04$ & $5.98 \mathrm{E}-04$ \\
60 & $2.27 \mathrm{E}-04$ & $1.67 \mathrm{E}-04$ & $2.15 \mathrm{E}-04$ \\
90 & $1.20 \mathrm{E}-04$ & $1.25 \mathrm{E}-04$ & $1.21 \mathrm{E}-04$ \\
180 & $3.12 \mathrm{E}-05$ & $6.53 \mathrm{E}-05$ & $3.80 \mathrm{E}-05$ \\
365 & $5.53 \mathrm{E}-06$ & $2.18 \mathrm{E}-05$ & $8.78 \mathrm{E}-06$ \\
\hline
\end{tabular}

(a) From PNNL-MA-860, Table 7.10 (Reference 2).

(b) Calculated as $80 \%$ Type $\mathrm{F}+20 \%$ Type $\mathrm{M}$. 
Table A.2. Screening levels for various periodic monitoring intervals for Hanford UO3 material, assuming acute inhalation of 5- $\mu$ m AMAD particles. $\{\mathrm{TA} \backslash 1$ "Table A.2. Screening levels for various periodic monitoring intervals for Hanford UO3 material, assuming acute inhalation of $5-\mu \mathrm{m}$

AMAD particles." \s "Table A.2. Screening levels for various periodic monitoring intervals for Hanford UO3 material, assuming acute inhalation of 5- $\mu \mathrm{m}$ AMAD particles." \c 1 \}

\begin{tabular}{|c|c|c|c|c|c|c|c|}
\hline $\begin{array}{l}\text { Monitoring } \\
\text { Interval } \\
\text { length (d) }\end{array}$ & $\begin{array}{l}\text { Intervals } \\
\text { per year }\end{array}$ & $\begin{array}{c}E(50) \text { for } \\
\text { interval } \\
\text { (mrem) }\end{array}$ & $\begin{array}{c}\text { Intake for } \\
\text { interval }^{(a)} \\
(\mathrm{mg})\end{array}$ & $\begin{array}{c}\text { Interval } \\
\text { Excretion } \\
\text { Fraction }^{(b)}\end{array}$ & $\begin{array}{c}\text { Reference } \\
\text { Level for } \\
\text { Interval } \\
\text { Intake }^{(\mathrm{c})} \\
(\mu \mathrm{g} / \mathrm{d})\end{array}$ & $\begin{array}{c}\text { Screening } \\
\text { Level }^{(\mathrm{d})} \\
(\mu \mathrm{g} / \mathrm{d})\end{array}$ & $\begin{array}{c}\text { Rounded } \\
\text { Screening } \\
\text { Level } \\
(\mu \mathrm{g} / \mathrm{d})\end{array}$ \\
\hline \multicolumn{8}{|c|}{ Design Goal \#1: 100 mrem E(50)/y } \\
\hline 365 & 1 & 100 & 32.9 & $8.78 \mathrm{E}-06$ & 0.29 & 0.49 & 0.5 \\
\hline 180 & 2 & 50 & 16.4 & $3.80 \mathrm{E}-05$ & 0.62 & 0.82 & 0.8 \\
\hline 90 & 4 & 25 & 8.21 & $1.21 \mathrm{E}-04$ & 0.99 & 1.19 & 1 \\
\hline 30 & 12 & 8.3 & 2.74 & $5.98 \mathrm{E}-04$ & 1.64 & 1.84 & 2 \\
\hline 14 & 26 & 3.8 & 1.26 & $1.64 \mathrm{E}-03$ & 2.07 & 2.27 & 2 \\
\hline \multicolumn{8}{|c|}{ Design Goal \#2: 10 mrem E(50)/y } \\
\hline 365 & 1 & 10 & 3.29 & $8.78 \mathrm{E}-06$ & 0.029 & 0.23 & 0.2 \\
\hline 180 & 2 & 5 & 1.64 & $3.80 \mathrm{E}-05$ & 0.062 & 0.26 & 0.3 \\
\hline 90 & 4 & 2.5 & 0.82 & $1.21 \mathrm{E}-04$ & 0.099 & 0.30 & 0.3 \\
\hline 30 & 12 & 0.83 & 0.27 & 5.98E-04 & 0.16 & 0.36 & 0.4 \\
\hline 14 & 26 & 0.38 & 0.13 & $1.64 \mathrm{E}-03$ & 0.21 & 0.41 & 0.4 \\
\hline \multicolumn{8}{|c|}{ Design Goal \#3: 10 mrem E(50) per measurement } \\
\hline 365 & 1 & 10 & 3.29 & $8.78 \mathrm{E}-06$ & 0.029 & 0.23 & 0.2 \\
\hline 180 & 2 & 10 & 3.29 & $3.80 \mathrm{E}-05$ & 0.12 & 0.32 & 0.3 \\
\hline 90 & 4 & 10 & 3.29 & $1.21 \mathrm{E}-04$ & 0.40 & 0.60 & 0.6 \\
\hline 30 & 12 & 10 & 3.29 & $5.98 \mathrm{E}-04$ & 2.0 & 2.2 & 2 \\
\hline 14 & 26 & 10 & 3.29 & $1.64 \mathrm{E}-03$ & 5.4 & 5.6 & 6 \\
\hline
\end{tabular}

(a) Calculated as E(50 for interval / UO3 e(50) of 3.04E-03 rem/mg-U.

(b) From Table A.1.

(c) Calculated as Intake for Interval $\times$ Interval Excretion Fraction.

(d) Calculated as Reference Level for Interval Intake $+0.2 \mu \mathrm{g} / \mathrm{d}$.

(e) Screening level rounded to one significant figure. 